\title{
Use of superabsorbent polymers (SAP) as concrete additive
}

\author{
Viktor Mechtcherine ${ }^{a^{*}}$ \\ ${ }^{a}$ TU Dresden, Institute of Construction Materials, Dresden, Germany
}

Received: 30 September 2016 / Accepted: 10 November 2016 / Published online: 29 November 2016

(C) The Author(s) 2016. This article is published with open access.

\begin{abstract}
Superabsorbent polymers (SAP) are new, very promising multipurpose chemical admixtures for concrete. They make available a number of new possibilities with respect to the control of free water in the mixture. In turn they contribute to the control of the rheological properties of fresh concrete and to the mitigation of autogenous and plastic shrinkage through internal curing. Furthermore, pore systems built up as a result of SAP addition seem to remain stable regardless of the consistency of the concrete, the addition of superplasticizers, or the method of placement and compacting. Thus, SAP can be used as an alternative to air-entrainment agents. This article presents these and other potential practical applications of SAP in concrete construction.
\end{abstract}

Keywords: Concrete additive; Superabsorbent polymers; Hydrogel; Autogenous shrinkage; Freeze-thaw resistance

\section{SAP as a new concrete additive}

In recent decades great advances in concrete technology have been made, to a large extent due to the development and use of new chemical additives. These additives, although added to concrete in very small quantities, can dramatically improve crucial characteristics of concrete in its fresh and/or hardened state.

One of the key considerations in concrete technology is gaining control over the water therein. The introduction of Superabsorbent polymers (SAP) as a new component for the production of concrete materials offers a number of new possibilities with respect to water control and, as a result, to the control over the rheological properties of fresh concrete, this in addition to purposeful water absorption and/or water release in either fresh or hardened concrete. The well controlled uptake and release of water can be fostered by the specific design of SAP materials adapted to particular practical needs. As examples of this, the internal curing of high-performance concrete (HPC) and the inducing of abrupt changes in rheological behaviour during shotcreting might be given here, but the potential for innovation is far wider.

Another persistent problem in modern concrete technology relates to the creation in concrete of advantageous pore systems which could improve its durability, especially in terms of freeze-thaw resistance. Contemporaneously, airentrainment agents are widely used for this purpose. However, the entrained air voids frequently are not stable enough to tolerate transport, compacting, or in some instances specific methods of application such as spraying. In contrast, pore systems built up as a result of SAP-addition seem to remain stable regardless of the consistency of the concrete, of the addition of super-plasticizer, or of the method of placement and compacting. Also, a number of further applications have been proposed, some as conceptual ideas as well as some supported by investigation.

The first patents on dry mortars containing superabsorbents were written by Dow and Hoechst as early as end of nineteen-eighties and the middle of nineties already, i. e. soon after the development of SAP in the 1980s. Following the pioneering work by Jensen and Hansen $[1,2]$ and the conference in 2006 [3], at which a number of contributions on application of SAP in concrete were presented, the increasing interest in the use of SAP as a concrete additive and the need for intensive scientific exchange among research groups led in 2007 to the convening of the RILEM Technical Committee 225-SAP "Application of Superabsorbent Polymers in Concrete Construction". The committee's main objective was to coordinate research efforts and compile the results of studies with respect to the effects of adding SAP on the properties of concrete in its fresh and hardened states. The main product of the committee's work was State-of-the-Art Report [4]. The report deals with all the aspects of the use of SAP in concrete, that is, the effects of adding SAP on concrete's rheological behaviour, shrinkage, strength, durability, and other properties as well as mechanisms of SAP-action on various concrete characteristics, such as the kinetics of water-absorption and desorption through SAP in addition to changes in concrete

* Corresponding author: Viktor Mechtcherine, mechtcherine@tu-dresden.de 
microstructure. Also, it served as starting point for further activity of RILEM TC 225-SAP, including two round-robin tests dealing with mitigation of autogenous shrinkage of HPC attributable to internal curing with SAP [5] and with enhancing the freeze-thaw resistance of concrete by addition of SAP [6]. Furthermore, RILEM TC 225-SAP organised two International RILEM Conferences on "Use of Superabsorbent Polymers and Other New Additives in Concrete" in Lyngby (Denmark, 2010) [7] and in Dresden (Germany, 2014) [8]. The proceedings of these conferences provide additional references to those provided by the Stateof-the-Art Report [4].

While the work cited covers all relevant aspects of SAP in concrete construction, this article gives a brief overview of key properties of SAP and of existing and potential practical applications of SAP as a new concrete additive.

\section{Relevant properties of SAP for concrete applications}

SAP were developed in the 1980s. Since then they have been used primarily in sanitary and convenience products [9]. The polymers can be synthesised in two principal ways. One is bulk polymerisation in substance, from which a block results. This is then crushed into small particles of the desired size and irregular shape, Fig. 1a. The other method is inversesuspension polymerisation, which produces spherical particles, Fig. 1b. Both methods allow the use of different manners of cross-linking, e.g., the addition of multivalent monomers in small amounts [9].

For their application in concrete, the following properties of SAP are of particular relevance:

- Chemical stability in ionic solutions;

- Absorption and desorption behaviour in concrete (or, alternatively, in cement paste filtrate), under pressure and at different temperatures;

- Particle size (distribution).

For use in construction covalently cross-linked polymers of acrylic acid and acrylamide, neutralised by alkalis have proven efficient. They must be chemically stable and able to swell in the strong alkaline saline solution of the liquid phase of the cement paste [10]. Depending on the particular purpose of the SAP in concrete, the exact knowledge of the kinetics of absorption and desorption of cement pore solution is essential. Figure 2 shows the behaviour of different SAP in cement pore solution (actually cement filtrate). While some SAP materials retain the absorbed ionic solution for hours and continue to swell, other polymers start to collapse shortly after absorbing the pore solution and subsequently release a great fraction of the water. This particular behaviour depends on the density of anionic functional groups, the cross-linking density of the polymers, and other chemical parameters [11]. The inherent sorption kinetics of SAP as observed in the experiments with cement pore solution mirror the behaviour of SAP in cement paste well, as proven by the investigation using neutron radiography imaging [12]. It was also shown that the solution-retentive types of SAP perform much better in comparison to the spontaneous-release types of SAP in terms of mitigating autogenous shrinkage [11] and enhancing the freeze-thaw resistance of concrete. Furthermore, the retentive SAP exhibit no negative effect on mechanical properties of concrete if added in appropriate quantity [11].
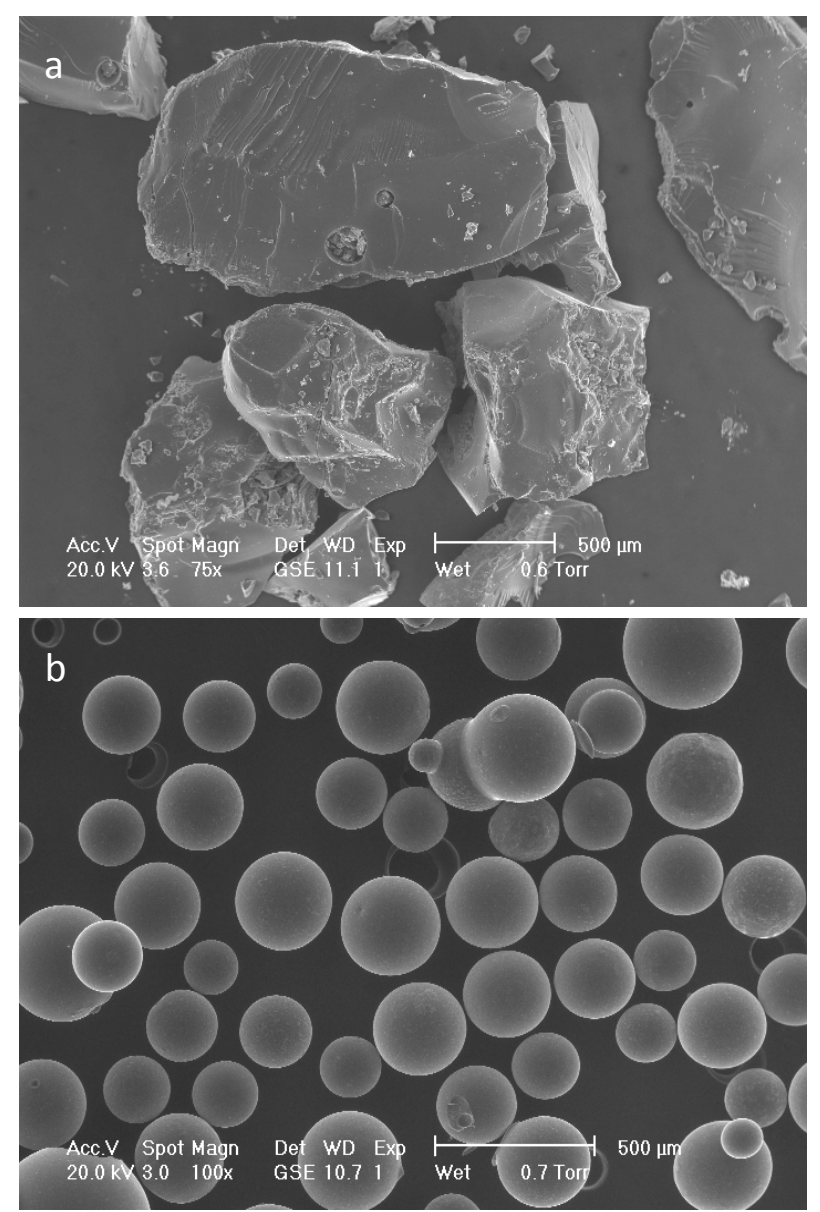

Figure 1. ESEM picture of dry SAP particles produced by a) bulk polymerization and $b$ ) inverse suspension polymerization

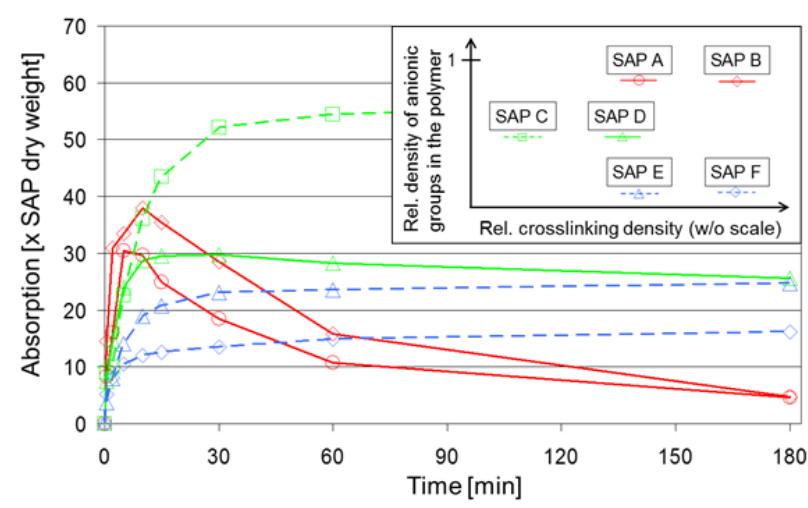

Figure 2. Absorption of different SAP materials in cement pore solution, after [11] 


\section{Application of SAP for mitigation of autogenous shrinkage}

Controlling early-age cracking due to volume changes in concrete structures is essential to their long-term durability. Today, many concrete structures experience early-age shrinkage cracking. Especially high-performance concretes have a significant susceptibility to damage caused by autogenous shrinkage due to their low water-to-binder ratios and to the associated self-desiccation process. Even in the first few days after pouring, autogenous shrinkage may lead to high restraint stresses and, thus, to crack formation in the concrete. Unlike drying shrinkage, autogenous shrinkage cannot be reduced significantly by external curing processes, since the dense microstructure of HPC allows only very limited water transport. One possible solution to this problem is internal curing triggered by inserting fine SAP particles that serve as small water reservoirs evenly distributed across the concrete volume when they have absorbed the water from the fresh concrete. As hydration progresses, SAP releases water as a result of underpressure in the surrounding matrix. This water supply counteracts two mechanisms which are likely to be responsible for the development of shrinkage deformations due to selfdesiccation: 1) a decrease in the disjoining pressure between the particles of the $\mathrm{C}-\mathrm{S}-\mathrm{H}$ gel, and 2) a decrease in the menisci radii of the pore water, which bespeaks an increase in tension both within the pore water and at its surface. The addition of SAP as internal curing agent was first suggested by Jensen and Hansen [1, 2]. Later, the effectiveness of this approach was demonstrated by a number of research groups in different countries [13-16] and as a result of the RILEM Round Robin Test performed by thirteen labs all over the world [5].

The quantity of dry SAP particles added to concrete for purpose of internal curing usually ranges between 0.1 and $0.6 \%$ bwoc, depending on the demand for internal curing water and on the absorption capacity of SAP in fresh concrete. The latter can be estimated from the amount of extra water added to the mixture containing SAP to keep the consistency (usually measured by slump tests) at the same level as measured for the reference mixture. This amount of additional water, acting as internal curing water, is supposed to be absorbed by the SAP and later provided for the hydration process. It must be mentioned here that the effect of SAP on the rheological properties of fresh concrete or mortar cannot be described comprehensively by the slump test alone since SAP addition influences yield stress and plastic viscosity to different extents [17]. Lura et al. [15] reported that for the given addition of SAP, larger SAP particles are more effective in mitigating autogenous shrinkage than smaller ones. Schröfl et al. [11] showed that the effect of internal curing strongly depends on absorption capacity of SAP in fresh concrete, the amount of SAP as well as of specific desorption kinetics of SAP resulting from their molecular structure, Fig. 3 and Section 2.

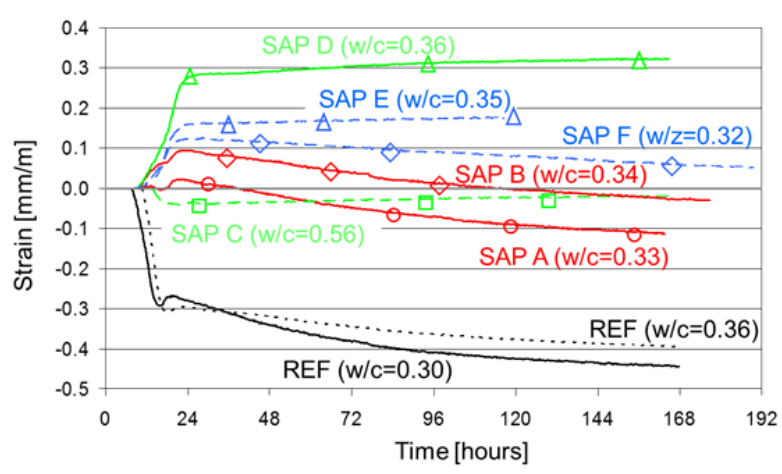

Figure 3. Results of dilatometer tests on the reference mortar and mortar modified with SAP (nomenclature according to Fig. 2); dosage of SAP $0.3 \%$ bwoc and $w / c$ adjusted to meet the slump flow value of $19 \mathrm{~cm} \pm 1 \mathrm{~cm}$. The differences in autogenous strain result from different molecular structure of SAP under investigation and subsequently from their various sorption behaviour.

Only a few investigations have been published on the detailed mechanisms and kinetics of water migration within the cement-based material, including, for example, migrating amounts of water from SAP into the surrounding matrix or the onset and duration of water release [13-15].

Wyrzykowski et al. [14] described a so-called "demandsupply mechanism". They found that liquid was extracted from swollen SAP at that point in time coincident with the first drop in internal relative humidity. Utilizing neutron tomography, Trtik et al. [16] visualized and quantified the water release from one SAP particle into a cement paste. They linked these kinetics to the progress of cement hydration and concluded that the onset of water release from their SAP particle coincided with the transition from the dormant to the acceleration period. This conclusion was supported in investigation conducted by Schröfl et al. [12], who observed intensive release of water at this stage for solution-retaining SAP particles (see Section 2) distributed in cement paste. Interestingly, such water release at a concrete age of two to three hours was measured not only for cement pastes with low water-to-cement ratio $(\mathrm{w} / \mathrm{c})$ of 0.25 , but also for those with $w / c=0.42$, with silica fume addition, and even with $\mathrm{w} / \mathrm{c}=0.5$; however, the kinetics were somewhat different in the last case. Such a w/c is clearly too high for the demands of classical internal curing, however, obviously also in this case, the underpressure resulting from chemical shrinkage is high enough to withdraw water of SAP.

The first constructed example in the world using SAPmodified, high-performance concrete is a pavilion consisting of slender precast elements built for the 2006 FIFA World Cup in Kaiserslautern, one of the host cities [18]. It was designed as a filigreed, thin-walled structure with very slender columns (minimum wall thickness of $20 \mathrm{~mm}$ ) and no conventional reinforcement, Fig. 4.

In order to meet the rigorous design requirements (including reduced autogenous shrinkage, high durability, enhanced ductility, self-compaction, and high-quality surface), selfcompacting, fibre-reinforced, high-performance concrete with internal curing was developed [18]. 
The concrete had a water-to-binder ratio $(w / b)$ of 0.21 and included CEM I 42.5 R HS cement and micro silica as binders, a blend of quartz powders and basalt sands, 6-mm steel fibers, and SAP with an average particle size of $200 \mu \mathrm{m}$. The content of SAP in the cement was $0.4 \%$ by mass, which was enough to be absorbed and subsequently provide up to 45 $\mathrm{kg} / \mathrm{m}^{3}$ of internal curing water to the concrete. The early-age autogenous shrinkage was greatly reduced by internal curing (from $605 \mu \mathrm{m} / \mathrm{m}$ to $72 \mu \mathrm{m} / \mathrm{m}$ after seven days).

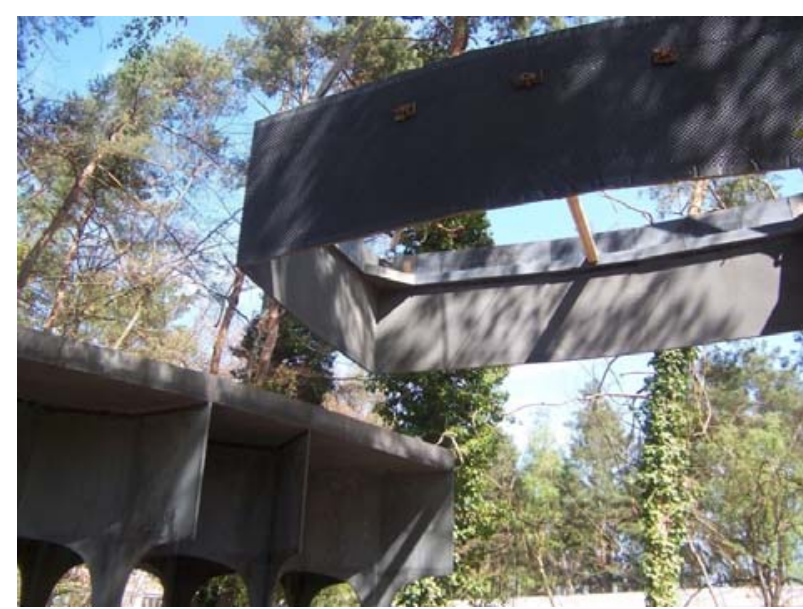

Figure 4. FIFA World Cup Pavilion, City of Kaiserslautern, Germany mounting the attic.

The largest application of SAP as internal curing agent thus far was carried out in Chinese railway construction [19]. About $800,000 \mathrm{~m}^{3}$ of bed slab concrete $(\mathrm{w} / \mathrm{b}=0.37)$ were cast in-situ for the second double line of the LanzhouUrumqi railway. SAP was successfully used in combination with a shrinkage-reducing admixture to prevent cracking in the concrete slabs in the windy, arid environment. Obviously in this case the purpose was not only to decrease autogenous shrinkage but also to make concrete less sensible to water loss due to evaporation. In this connection it should be mentioned that the addition of SAP can also reduce the plastic shrinkage of various types of concrete [20, $21,22]$. The addition of SAP slows down considerably the capillary pressure build-up, which results in a decrease in plastic shrinkage and in the related cracking of ordinary concrete [20, 21], ultra-high performance concrete [20], strain-hardening cement-based-composites [21, 22] and textile-reinforced concrete [22].

\section{Application of SAP to improve frost resistance}

Another challenge facing modern concrete technology is the specific design of the void structure in order to improve or optimize durability. To increase the frost resistance of concrete, air-entraining agents are used during the mixing process to create fine spherical voids. Air entrainment with conventional air-entraining admixtures often encounters technical difficulties such as coalescence of air bubbles in fresh concrete, loss of air during consolidation or pumping, chemical incompatibility with superplasticizers, etc. Therefore, such a void system is often unstable, with the result that the uniform distribution of air voids and the void size in the hardened concrete are extremely difficult to ensure. This problem can be resolved by adding SAP particles, whose size and distribution are easy to control and whose behaviour is very stable since this technology is uninfluenced by pumping and placing procedures. After water release to the matrix, SAP particles create voids which act in a fashion similar to that of fine air voids, see Fig. 5 .

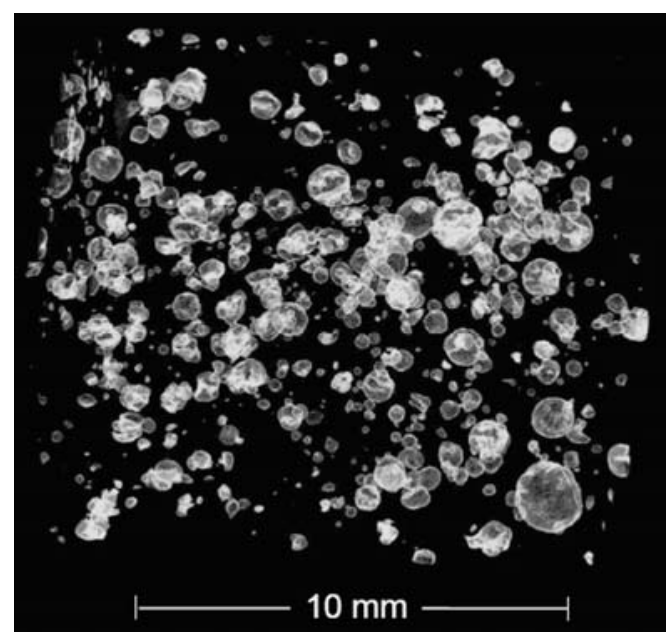

Figure 5. CT image of SAP void distribution in hardened cement paste.

The positive effect of added SAP on the freeze-thaw resistance of ordinary concrete was suggested by Jensen and Hansen [1] and demonstrated under laboratory conditions by Reinhardt et al. [23] and Laustsen et al. [24], where mixtures containing specific types of SAP were found to provide increased resistance to freezing and thawing in the presence of de-icing chemicals.

The performance of two different SAP types as an admixture aimed at evaluating the enhancement of freeze-thaw resistance in ordinary concrete was tested and analysed within the framework of the activities of the RILEM TC 225SAP [6]. Concretes with a w/c of 0.45 and 0.50 were tested, either with or without SAP, or with or without air-entraining agents. For most participants of the interlaboratory study the effect on freeze-thaw resistance of the addition of SAP together with additional water varied from insignificant to pronouncedly positive, depending on the testing laboratory and the test method. The finer SAP performed consistently better in this regard. When SAP had been added without additional water, the concrete performance was considerably improved. Fig. 6 shows exemplarily the result of CIF tests (i.e. freeze-thaw tests without deicing salts) on concrete with and without SAP addition.

At the TU Dresden the freeze-thaw resistance of highly ductile short-fibre reinforced concrete $($ SHCC $=$ Strainhardening, cement-based composite) was considerably improved by using SAP. Still further, SAP were shown to fulfil additional functions in this material. Indeed they are involved in inducing into the material structure specific micro-defects which contribute to activating fibre action [25]. In this conjunction as well the use of SAP as a multifunctional additive was demonstrated. The approach 
was to improve several properties of SHCC simultaneously, using to advantage various aspects of action of SAP. The SAP particles act as micro-defects which trigger the formation of multiple cracks when SHCC is subjected to high tensile loading, thereby increasing its ductility. At the same time SAP acts as an additive for increasing freeze-thaw resistance of the composite and as an internal curing agent.

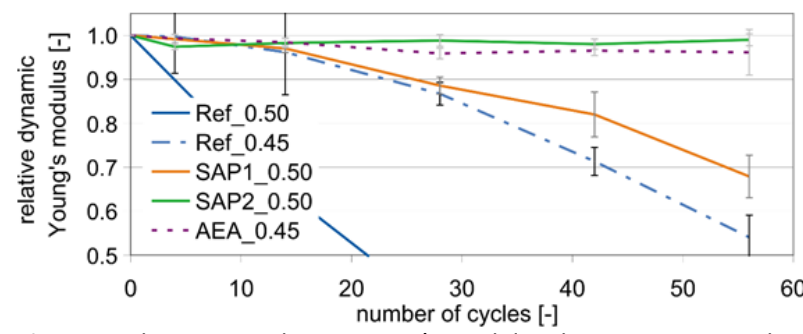

Figure 6. Changes in relative Young's modulus during CIF test at the TU Dresden; numbers after_ give the total w/c of concrete; concrete with addition of SAP 2 and $w / c=0.50$ shows a similar frost resistance as concrete with air entrainment agent $(A E A)$ and $w / c=0.45$.

The first practical application of SAP worldwide as an additive to increase the frost resistance of concrete was conducted in summer 2011, when SHCC developed at the TU Dresden was used to repair the upper water reservoir of the pumping hydraulic power station Hohenwarte II in Thüringen, Germany, see Fig. 7. Since the reservoir walls are exposed to high water saturation and considerable changes in water level, the danger of frost damage is considerable. In practice the use of conventional air-entrainment agents is possible with SHCC, but not when the spraying technique is applied. For this reason SAP was introduced as a new additive to improve the frost resistance of the repair layer.

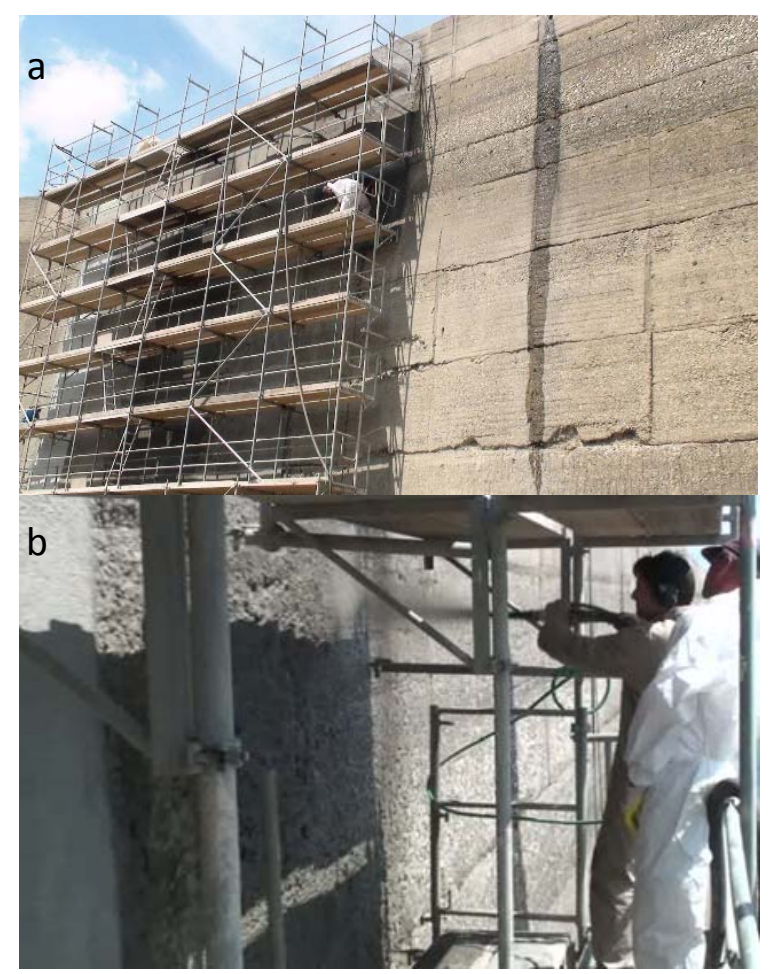

Figure 7. a) Condition of the upper water reservoir of the pumping hydraulic power station Hohenwarte II in Thüringen, Germany before repair, b) spray-application of highly ductile, cement-based composite containing SAP as repair material

\section{Further potential use of SAP in concrete construction}

\subsection{Rheological modification of shortcrete}

The use of SAP to increase the viscosity and decrease the rebound of shotcrete was the subject of a 1991 patent application from Snashall [26], who among other things proposed the premixing of SAP with the aggregate and $10 \%$ to $15 \%$ of the aggregate's weight of water, followed by a 10 minute stand in the mixer. Finally the cement and the rest of the mix water were then added, according to the formula. According to a later patent application from Jensen and Hansen [27], SAP can be added (i) dry in the nozzle to reduce the viscosity of a wet mix or (ii) completely or partially preswollen for internal curing purposes. In the first case, very rapid absorption of the SAP is desired to obtain a reduced viscosity before the shotcrete hits the wall. The second case has no such special requirement.

\subsection{Controlled release and self-healing}

SAP may also be used to control the release of not purely aqueous substances absorbed into the SAP particles. Substances which are initially at a higher activity in the polymer will diffuse out of the particles into their surroundings according to Buchholz and Graham [9]. Compared to other absorbent polymers, SAP have a special feature; their swelling depends on the $\mathrm{pH}$ of the swelling medium [9], which is a feature that may be used as a switch to provide for controlled release. One possible use of SAP as a controlled release agent in concrete could be for particular plasticizing admixtures which are more effective if they are first released shortly after initial contact between water and cement, and this at a time in which the $\mathrm{pH}$ of fresh concrete is relatively high. Furthermore, $\mathrm{pH}$ sensitive SAP were suggested for self-healing of cracked concrete [28].

\subsection{Waterproofing}

The volume increase of a gel of water-saturated, swollen SAP can be used to form a barrier to water flow. Sealing composites made by blending modified SAP into rubber (Tsubakimoto et al. [29]) or a thermoplastic elastomer [30] have been developed for sealing the joints of various building materials. The composite may be used as mortar in joints and, if any gaps were left during construction or created after construction due to settlement, the SAP swells when in contact with leaking water and forms a seal, as suggested by Shimomura and Namba [31]. According to [9], such a composite was used in the construction of the Channel Tunnel between France and England.

More examples of the potential uses of SAP in concrete construction can be found in $[4,7,8,32]$. 


\section{Outlook}

The wide use of SAP in concrete construction is still to come. Researchers and practitioners in different countries around the world are presently intensively investigating possibilities and limits of using SAP for solving various problems encountered by practitioners in the field. There are also first promising pilot applications which encourage companies and scientists to advance the use of this new additive in concrete construction. However, the step from the research lab into the practice of construction requires considerable effort. In the first place, the practitioners need clear recommendations as to which cases and how SAP can or should be used, how to consider addition of SAP and possibly internal curing water in concrete mix design, and how to estimate the effect of SAP addition on various properties of concrete in its fresh and hardened state. To answer such questions a new RILEM Technical Committee TC260-RSC "Recommendations for Use of Superabsorbent Polymers in Concrete Construction" was initiated in 2014. The main objectives of the committee are to collect and analyse information on applications of SAP in concrete, to initiate necessary research activities for clarifying open questions related with practical use of SAP, and, most importantly, to develop practical recommendations for utilizing SAP in concrete construction. Four recommendations should be prepared: (1) for testing SAP as concrete additive, (2) for using SAP to mitigate plastic shrinkage cracking, (3) for using SAP to mitigate autogenous shrinkage, and (4) for using SAP for improving durability (with a focus on freeze-thaw resistance). Within the framework of the preparation of the first two recommendations, round-robin tests will be performed. The recommendations are planned to be published before 2020 . TC260-RCS plans also another international RILEM conference on use of SAP in concrete construction and a corresponding $\mathrm{PhD}$ course.

\section{References}

[1] O.M. Jensen, P.F. Hansen, Water-entrained cement-based materials I. Principles and theoretical background. Cem Concr Res (2001) 31: 647-654. https://doi.org/10.1016/S0008-8846(01)00463-X

[2] O.M. Jensen, P.F. Hansen, Water-entrained cement-based materials II. Experimental observations. Cem Concr Res (2002) 32: 973-978. https://doi.org/10.1016/S0008-8846(02)00737-8

[3] O.M. Jensen, P. Lura, K. Kovler (Eds.), Volume Changes of Hardening Concrete: Testing and Mitigation. Proceedings of International Conference, RILEM Publications, PRO 52, 2006.

[4] V. Mechtcherine, H.W. Reinhardt (Eds.), Application of superabsorbent polymers in concrete construction. RILEM State of the Art Reports 2, Springer, 2012.

[5] V. Mechtcherine, M. Gorges, C. Schroefl, A. Assmann, W. Brameshuber et al., Effect of internal curing by using superabsorbent polymers (SAP) on autogenous shrinkage and other properties of a high-performance fine-grained concrete: results of a RILEM round-robin test. Mater Struct (2014) 47: 541-562. https://doi.org/10.1617/s11527-013-0078-5

[6] V. Mechtcherine, C. Schröfl, M. Wyrzykowski, M. Gorges, P. Lura et al., Effect of superabsorbent polymers (SAP) on the freeze-thaw resistance of concrete: results of a RILEM interlaboratory study. Mater Struct (2017) 50: 14. https://doi.org/10.1617/s11527-016-0868-7
[7] O.M. Jenssen, M.T. Hasholt, S. Laustsen (Eds.), Use of Superabsorbent Polymers and Other New Additives in Concrete. Proceedings of International Conference, RILEM Publications, PRO 74, 2010.

[8] V. Mechtcherine, C. Schröfl (Eds.), Application of superabsorbent polymers and other new admixtures in concrete construction. Proceedings of International Conference, RILEM Publications, PRO 95, 2014.

[9] F.L. Buchholz, A.T. Graham, Modern Superabsorbent Polymer Technology. WILEY VCH, New York (USA), 1998.

[10] A. Pourjavadi, R. Soleyman, G.R. Barajee, Novel Nanoporous Superabsorbent Hydrogel based on Poly(acrylic acid) Grafted onto Salep: Synthesis and Swelling Behavior. Starch/Stärke (2008) 60: 467-475. https://doi.org/10.1002/star.200700706

[11] C. Schröfl, V. Mechtcherine, M. Gorges, Relation between the molecular structure and the efficiency of superabsorbent polymers (SAP) as concrete admixture to mitigate autogenous shrinkage. Cem Concr Res (2012) 42: 865-873. https://doi.org/10.1016/i.cemconres.2012.03.011

[12] C. Schroefl, V. Mechtcherine, P. Vontobel, J. Hovind, E. Lehmann Sorption kinetics of superabsorbent polymers (SAPs) in fresh Portland cement-based pastes visualized and quantified by neutron radiography and correlated to the progress of cement hydration. Cem Concr Res (2015) 75: 1-15. https://doi.org/10.1016/i.cemconres.2015.05.001

[13] L. P. Esteves, Internal curing in cement-based materials. PhD Thesis, Universidade de Aveiro, 2009.

[14] M. Wyrzykowski, P. Lura, F. Pesavento, D. Gawin, Modeling of internal curing in maturing mortar, Cem Concr Res (2011) 41: 13491356. https://doi.org/10.1016/j.cemconres.2011.04.013

[15] P. Lura, F. Durand, O.M. Jensen, Autogenous strain of cement pastes with superabsorbent polymers. In: O.M. Jensen, P. Lura, K. Kovler (Eds.), Volume Changes of Hardening Concrete: Testing and Mitigation, Proceedings of International Conference, RILEM Publications, PRO 52, 2006, 57-66.

[16] P. Trtik, B. Münch, W.J. Weiss, G. Herth, A. Kaestner, E. Lehmann, P. Lura, Neutron tomography measurements of water release from superabsorbent polymers in cement paste. In: W. Brameshuber (Ed.), Material Science, Additions Improving Properties of Concrete, Proceedings of International Conference, RILEM Publications, PRO 77 (3), 2010, 175-185.

[17] V. Mechtcherine, E. Secrieru, C. Schroefl, Effect of superabsorbent polymers (SAPs) on rheological properties of fresh cement-based mortars - Development of yield stress and plastic viscosity over time. Cem Concr Res (2015) 67: 52-65. https://doi.org/10.1016/i.cemconres.2014.07.003

[18] V. Mechtcherine, L. Dudziak, J. Schulze, H. Staehr, Internal curing by super absorbent polymers (SAP) - Effects on material properties of self-compacting fibre-reinforced high performance concrete. In: O.M. Jensen, P. Lura, K. Kovler (Eds.), Volume Changes of Hardening Concrete: Testing and Mitigation, Proceedings of International Conference, RILEM Publications, PRO 52, 2006, 87-96.

[19] C. Zhu, X. Li, Y. Xie, Influence of SAP on the Performance of Concrete and its Application in Chinese Railway Construction. In: V. Mechtcherine, C. Schröfl (Eds.), Application of superabsorbent polymers and other new admixtures in concrete construction, Proceedings of International Conference, RILEM Publications, PRO 95, 2014, 345-354.

[20] V. Mechtcherine, L. Dudziak, Effects of Superabsorbent Polymers on Shrinkage of Concrete: Plastic, Autogenous, Drying. In: V. Mechtcherine, H.W. Reinhardt (Eds.), Application of superabsorbent polymers in concrete construction, RILEM State of the Art Reports 2 , Springer, 2012, 67-106. https://doi.org/10.1007/978-94-007-2733-5 7

[21] I. Serpukhov, V. Mechtcherine, Early-Age Shrinkage of Ordinary Concrete and a Strain-Hardening Cement-Based Composite (SHCC) in the Conditions of Hot Weather Casting. Proceedings of CONCREEP 10, ACSE, 2015, 1504-1513.

[22] V. Mechtcherine, I. Serpukhov, M. Butler, Plastic shrinkage of thin layers of strain-hardening cement-based composite (SHCC) and textile-reinforced concrete (TRC). In: N. Banthia, M. Di Prisco, S. Soleimani-Dashtaki (Eds.), Proc. of 9th RILEM International Symposium on Fiber Reinforced Concrete - BEFIB 2016, RILEM Publications, PRO 116, 2016, 438-447.

[23] H.W. Reinhardt, A. Assmann, S. Mönnig, Superabsorbent polymers (SAP) - an admixture to increase the durability of concrete. Proc. of the 1st International Conference on Microstructure Related 
Durability of Cementitious Composites, Nanjing, China, 2008, 313322.

[24] S. Laustsen, M.T. Hasholt, O.M. Jensen, A new technology for air entrainment of concrete. Proc. of the 1st International Conference on Microstructure Related Durability of Cementitious Composites, Nanjing, China, 2008, 1223-1230.

[25] A.E. Brüdern, V. Mechtcherine, Multifunctional use of SAP in Strainhardening Cement-based Composites. In: O.M. Jenssen, M.T. Hasholt, S. Laustsen, (Eds.), Use of Superabsorbent Polymers and Other New Additives in Concrete, Proceedings of International Conference, RILEM Publications, PRO 74, 2010, 11-22.

[26] H.T. Snashall, Cementitious mixes, South African Patent Application ZA9100876 A 19911224, 1991.

[27] O.M. Jensen, P.F. Hansen, Water-entrained cement-based materials, PCT Patent Application WO01/02317A1, 2001.

[28] D. Snoeck, K. Van Tittelboom, S. Steuperaert, P. Dubruel, N. De Belie, Self-healing cementitious materials by the combination of microfibres and superabsorbent polymers. Journal of Intelligent Mater Sys Struct (2014) 25: 13-24. https://doi.org/10.1177/1045389X12438623

[29] T. Tsubakimoto, T. Shimomura, H. Kobayashi, Japan, Kokai Tokkyo Koho, 62-149, 335, 1987.

[30] Suetsugu: Japan, Kokai Tokkyo Koho, 06-157, 839, 1994

[31] T. Shimomura, T. Namba, Superabosorbent Polymers, Science and Technology, In: F. L. Buchholz, N. A. Peppas (Eds.), Symposium Series 573, American Chemical Society, Washington DC, 1994, 112-115.

[32] M. Wyrzykowski, P. Lura, Controlling the coefficient of thermal expansion of cementitious materials - a new application for superabsorbent polymers. Cem Concr Comp (2013) 35: 49-58. https://doi.org/10.1016/j.cemconcomp.2012.08.010 